\title{
Aspectos cognitivos em oficinas de jogos para a aprendizagem da língua estrangeira
}

\author{
Claudia Ferrareto Lopes \\ Universidade Estadual de Londrina, Londrina - PR - Brasil \\ claudialps@gmail.com \\ Francismara Neves de Oliveira \\ Departamento de Educação e Programa de Pós-Graduação em Educação da Universidade Estadual de Londrina- \\ $P R$ - Brasil \\ francis.uel@gmail.com
}

EDUCAÇÃO: Teoria e Prática, Rio Claro, SP, Brasil - eISSN: 1981-8106

Está licenciada sob Licença Creative Common

\section{Resumo}

O artigo apresentado objetivou analisar os aspectos cognitivos, relacionados à aprendizagem da língua inglesa como idioma estrangeiro, por meio de oficinas de jogos, com alunos do 60 ano do ensino fundamental de uma escola estadual, no município de Londrina. A base deste estudo é a teoria Piagetiana na modalidade de estudo descritivo-interpretativo, sob uma perspectiva qualitativa. Duas questões norteadoras se interpõem: qual o papel das oficinas com jogos para a aprendizagem da língua inglesa como idioma estrangeiro? De que maneira os processos cognitivos se apresentam nas oficinas de jogos para a aprendizagem do inglês? Para atingir os objetivos propostos, foram realizadas oficinas com jogos nos quais o conteúdo da língua inglesa foi trabalhado. As oficinas possibilitaram a observação e a análise de aspectos cognitivos envolvidos na aprendizagem da segunda língua. Os resultados mostraram que as oficinas promovem a participação dos alunos, pois suscitam a ação e produção do sujeito, evidenciam lacunas no conhecimento e propiciam processos de equilibração. Por meio das demandas dos jogos, os sujeitos são convidados a produzir, o que suscita o saber-fazer, bem como refletir sobre suas produções, o que sugere um processo de tomada de consciência.

Palavras-chave: Aprendizagem da língua estrangeira. Jogos de regras. Oficina de jogos.

\section{Cognitive aspects in games workshops for learning a foreign language}

\footnotetext{
Abstract

The goal of the study was to analyze the cognitive aspects related to learning English as a foreign language, by means of games workshops with students of the $6^{\text {th }}$ grade of
} 
elementary school from a state school in Londrina. The paper is grounded on Piagetian theory and is descriptive-interpretative study with a qualitative perspective. Two guiding questions motivate the study: what is the role of games workshops for learning English as a foreign language? In what way the cognitive processes are held in the games workshops for learning English? To meet the proposed goals, workshops were implemented with games containing the linguistic contents studied in English classes. The games workshops enabled the observation and analysis of the cognitive aspects involved in learning a foreign language. Results show that the games workshops promote the participation of the students motivating action and output, evidencing gaps on the knowledge and providing equilibration processes. Subjects are asked to produce outputs via games demands, thus evoking knowhow, as well as the thinking about their own products, suggesting a conscious-awareness process.

Keywords: Foreign language learning. Rule based games. Games workshops.

\section{Aspectos cognitivos en talleres de juegos para el aprendizaje de lengua extranjera}

\section{Resumen}

El artículo presentado tuvo como objetivo analizar los aspectos cognitivos, relacionados al aprendizaje de la lengua inglesa como idioma extranjero, por medio de talleres de juegos, con alumnos del 60 año de la enseñanza fundamental de una escuela estadual, en el municipio de Londrina. La base de este estudio es la teoría piagetiana en la modalidad de estudio descriptivo-interpretativo, bajo una perspectiva cualitativa. Dos preguntas orientadoras se interpusieron: ¿cuál es el papel de los talleres con juegos para el aprendizaje de la lengua inglesa como idioma extranjero? ¿De qué manera los procesos cognitivos se presentan en los talleres de juegos para el aprendizaje del inglés? Para alcanzar los objetivos propuestos se realizaron talleres con juegos en los que se trabajó el contenido de lengua inglesa. Los talleres posibilitaron la observación y el análisis de aspectos cognitivos involucrados en el aprendizaje de la segunda lengua. Los resultados mostraron que los talleres promueven la participación de los alumnos, pues suscitan la acción y la producción del sujeto, evidencian lagunas en el conocimiento y propician procesos de equilibrio. Por medio de las demandas de los juegos, los sujetos son invitados a producir, lo que suscita el saber-hacer, así como la reflexión sobre sus producciones, lo que sugiere un proceso de concienciación.

Palabras clave: Aprendizaje de lengua extranjera. Juegos de reglas. Taller de juegos.

\section{Introdução}

O domínio de um idioma estrangeiro é considerado um fator importante na configuração social atual, advindo do crescente intercâmbio entre culturas distintas, propiciado pelo aprimoramento de tecnologias e dos meios de comunicação. Como exemplo, temos a popularização da internet possibilitando tanto o contato com diversos 
idiomas como com as manifestações culturais de cada povo onde esse idioma é adotado. Assim, o domínio de outra língua adquire significados distintos a depender do contexto em que é requerido.

Duarte (2007) analisa o cenário nacional e mundial em relação aos modos de produção e economia, constatando que, no panorama atual, a aprendizagem da língua estrangeira não se propõe apenas a possibilitar comunicação entre os povos, mas busca atender demandas do mercado mundial. Como reflexo desse contexto, percebemos um aumento na demanda por ensino de língua estrangeira e a multiplicação de escolas e centros de línguas. Pires (2004) assinala, em sua reflexão, o aumento da demanda de aulas de língua estrangeira em escolas particulares de ensino fundamental. Destaca a preferência por escolas que ofertam o inglês desde os anos iniciais e argumenta que a ampliação da oferta dessa disciplina, desde o início do processo de escolarização, pode propiciar uma aprendizagem mais aprofundada e domínio do idioma.

Destacamos, entretanto, que a demanda em relação ao ensino da língua estrangeira não se reflete apenas na esfera do ensino particular. Os documentos norteadores da educação como a Lei de Diretrizes e Bases (LDB) e os Parâmetros Curriculares Nacionais (PCNs) balizam o trabalho com a língua estrangeira nas escolas. Os documentos indicam que a escola pública deve ofertar a seus alunos a disciplina de língua estrangeira moderna, conferindo aos mesmos a possibilidade de se comunicar, ler, ouvir e compreender. A oferta é obrigatória a partir da quinta série (60 ano) do Ensino Fundamental (BRASIL, 2010, p. 24).

Sobre o mesmo tema, os Parâmetros Curriculares Nacionais - Língua Estrangeira apontam que a aprendizagem da língua estrangeira, assim como a da língua materna, constitui direito de todo cidadão brasileiro, devendo a escola oferecer condições para esta aprendizagem, enfatizando a comunicação em outro idioma, de modo a se envolver com outros no discurso. Isso deve ser possibilitado em sala de aula, por meio de atividades pedagógicas via língua estrangeira (BRASIL, 1998, p. 19-20).

De acordo com o artigo apresentado por Guerra e Camargo (2012), a língua inglesa está presente no cenário brasileiro em diferentes formas de contato tais como rótulos de produtos importados, músicas veiculadas nas rádios, bem como no eventual contato com estrangeiros em visita a nosso país, suscitando a necessidade de atentar para a propriedade comunicativa da língua, fundamental à compreensão. As demandas atuais do mercado de 
trabalho brasileiro por profissionais que dominam a língua inglesa, bem como a necessidade de comunicação e expressão no idioma citado na internet e demais meios de comunicação, contribuem para a necessidade de aprender a língua inglesa.

Compreendendo que a língua não se restringe a um sistema, mas que em seu funcionamento permite a comunicação, a proposta deste estudo foi analisar os aspectos cognitivos em oficina de jogos para aprendizagem da língua estrangeira. Para tal proposta, a oficina com jogos se mostrou pertinente para oferecer um contexto ou ambiente comunicativo entre os participantes. Partimos de duas questões norteadoras: qual o papel das oficinas com jogos para a aprendizagem da língua inglesa como idioma estrangeiro? De que maneira os processos cognitivos se apresentam nas oficinas de jogos para a aprendizagem do inglês? O estudo esteve ancorado na perspectiva Piagetiana, tendo como eixo principal os processos da equilibração ${ }^{1}$ - central no desenvolvimento - integrando as assimilações e acomodações, invariantes funcionais do desesenvolvimento. Nesse campo teórico, compreende-se que a construção do conhecimento ocorre por meio do processo de equilibração, promovendo a adaptação da estrutura cognitiva e mudança qualitativa e quantitativa do conjunto de esquemas que compõem o sistema cognitivo.

\section{Reflexões acerca dos processos de equilibração na aprendizagem da segunda língua}

Na obra Piagetiana, o fazer e o compreender são integrados no processo de conhecer, o que está intimamente relacionado ao processo de equilibração. Nessa perspectiva teórica, equilibração é compreendida como o "problema central do desenvolvimento", como indicado no título da obra do autor, Piaget (1976, p.19). Na obra, o autor se refere "às assimetrias entre negações e afirmações. Os desequilíbrios constituem-se desencadeadores, mas não garantem por si só, uma reequilibração no sentido de um equilíbrio melhor".

De acordo com Macedo (1994), os desequilíbrios não têm origem demarcada num fator interno ou externo ao sujeito, incidindo sobre as não correspondências entre negações e afirmações. As negações são resultantes de um processo mais complexo que o das

\footnotetext{
${ }^{1}$ De acordo com Piaget (1976, p. 11), o processo de equilibração "conduz de certos estados de equilíbrio aproximado a outros, qualitativamente diferentes, passando por múltiplos desequilíbrios e reequilibrações." Implicam em uma modificação do sistema cognitivo, uma vez que não são mecânicos e não conduzem ao estado de equilíbrio anterior.
} 
afirmações, pois implica em um não ser, não fazer. O autor ressalta, ainda, que "o progresso do conhecimento consiste justamente nessa busca incessante de eliminação das contradições" (MACEDO, 1994, p. 151). Por essa razão, as afirmações são mais frequentes no desenvolvimento inicial e as negações, construções mais tardias.

O processo de equilibração é permeado por regulações, que, segundo Piaget (1976), caracterizam a maneira como ocorrem as equilibrações e as reequilibrações. Macedo (1994, p. 151), ao explicar as reações às perturbações, lembra que só se pode afirmar que há de fato uma perturbação quando "o sujeito possui uma estrutura capaz de assimilar o evento perturbador". Ou seja, haverá desequilíbrio cognitivo quando a estrutura já é capaz de reconhecê-lo como tal, desencadeando uma regulação.

As classes de perturbações expostas por Piaget (1976) são divididas em relação à sua origem. As perturbações advindas de erros ou fracassos propiciam feedbacks negativos, ou seja, oportunizam (mas não garantem) uma modificação na ação. São opostas às adaptações, concorrentes aos esforços de adaptação do sujeito. Já as perturbações originadas por lacunas e insuficiência de conhecimentos necessários ao sujeito podem levar a um feedback positivo, prolongando a atividade assimiladora do esquema. Porém, quando o sujeito reage à perturbação, aplicando a mesma ação tendo em vista sucesso, ou ainda, quando dirige sua atividade em outra direção, não se pode dizer que houve regulação (PIAGET, 1976).

De acordo com Montangero e Maurice-Naville (1998), a regulação representa uma autocorreção, ou seja, um mecanismo interno pelo qual o sujeito realiza modificações em seus esquemas em busca de um equilíbrio melhor. Em Dell'Agli (2002), confere-se que as regulações são formas de o sujeito reagir à perturbações. Podem ser classificadas como automáticas, requerendo pouca variação na ação do sujeito, ou ativas, que exigem uma mudança maior nos meios empregados e implicam em escolha. Apesar de tênue a linha que as divide, uma diferença central as demarca. Nas regulações automáticas, não está implicada a tomada de consciência, ao passo que, as regulações ativas, provocam e constituem-se como "a origem de uma representação ou conceituação das ações materiais" (PIAGET, 1976, p. 27).

No mecanismo de qualquer regulação, há intervenção de dois processos de sentidos opostos: um processo retroativo, que conduz o resultado de uma ação ao seu recomeço; e outro proativo, que conduz a uma correção ou a um reforço. Uma é a negação da outra e há, 
nisto, uma preparação para reversibilidade, uma vez que as correções levam às negações (DELL'AGLI, 2002).

Para a aprendizagem e domínio de uma segunda língua, tanto o saber fazer quanto a tomada de consciência da ação são relevantes, pois os dois processos possibilitam ao sujeito a utilização de um conhecimento por meio da ação prática, que, no caso da língua estrangeira, envolve a comunicação e o aprimoramento das produções e reconhecimento dos meios utilizados via tomada de consciência da ação.

Das relações interdependentes existentes entre partes e todo, declina-se a compreensão de que a comunicação em um idioma estrangeiro integra tanto elementos relativos à forma quanto ao conteúdo dessa comunicação, supõe, ainda, ação ativa do sujeito ao mesmo tempo em que o objeto de conhecimento se dá a conhecer pela via das contradições que oferece ao sistema. Essa relação contínua e progressiva envolve antecipações, pré-correções e inferências.

Tomemos como exemplo, o que analisa Piaget (1993) a partir dos experimentos realizados com provas de compreensão em crianças de 9 a 11 anos, nas quais o sincretismo pode ser observado. Foram apresentados provérbios, depois misturadas frases que apresentavam o mesmo sentido do provérbio, escrito de outra maneira. Pediu-se que o sujeito encontrasse a frase correspondente ao provérbio. Os alunos tendiam a não pedir explicações, presumindo que haviam compreendido o sentido literal e oculto dos provérbios, assimilando segundo seus esquemas. Alguns alunos que acreditavam ter compreendido os provérbios encontraram sentenças que, em sua ótica, eram correspondentes, o que não se confirma pela lógica adulta.

O produto desse sincretismo na compreensão é que a criança, ao ouvir uma mensagem com palavras que não compreende (ausência de tomada de consciência), tende a ignorar as partes que não compreendeu (negação da relação parte-todo), ligando as demais palavras, fazendo um esquema de conjunto, efetuando uma compreensão possivelmente equivocada da mensagem (inferências).

Piaget (1993), para ilustrar o sincretismo na compreensão, apresenta o exemplo de um adulto que lê um texto em uma língua estrangeira, da qual não tem muito conhecimento, podendo compreender frases sem obter a compreensão de cada termo individualmente: é constituído assim um esquema de conjunto. Esse esquema leva o sujeito a compreender as 
frases com apenas algumas ligações entre um ponto e outro, e essa compreensão pode ou não estar equivocada.

O que ocorre com o sujeito é que, ao ouvir a mensagem, busca assimilar o que foi dito ao seu ponto de vista, sem adaptar-se realmente ao outro, conduta explicada pela centralização do pensamento em uma única perspectiva. No sincretismo da percepção, portanto, o esquema de conjunto e o detalhe são solidários (a relação se dá apenas entre as partes e não ainda entre as partes e o todo - circularidade dialética). Progressivamente, o sujeito vai oscilando entre ambos até que passe a analisar a parte com maior domínio, sintetizando cada vez mais o todo.

No início da aprendizagem da segunda língua, só os aspectos mais evidentes são percebidos (afirmações), e só os esquemas de conjunto (mais gerais) são construídos. Consequentemente, os detalhes marcantes e a figura de conjunto são mais ou menos confundidos; depois, graças a esse sincretismo inicial, a análise e a síntese desenvolvem-se de modo interdependente, complementando-se e desencadeando cada vez análises mais aprofundadas das partes e sintetização do todo (PIAGET, 1993, p. 148).

De acordo com Piaget (1993), no raciocínio sincrético, então, há relações entre analogias explícitas e implicação de esquemas globais, encadeando um continuum entre o sincretismo da percepção e a compreensão cuja evolução só é possível por meio de sucessivas tomadas de consciência.

No contexto da tomada de consciência, o jogo é considerado como uma das formas que o ser humano emprega para ter prazer, relacionar-se e, sobretudo, conhecer. Ao longo de seu desenvolvimento, o sujeito se envolve em brincadeiras que vão desde repetições motoras aos mais elaborados jogos de estratégia. No recorte desta pesquisa, será contemplado o tipo de jogo que envolve regras. ${ }^{2}$

Os jogos, por conterem em sua estrutura possibilidades de interação sujeito-objeto, oportunizando momentos de ação e tomada de consciência, lançam demandas ao sujeito para que supere seu estado atual.

Piaget (1975) define os jogos de regras como uma combinação de atividades sensóriomotoras ou intelectuais, permeadas pelo aspecto competitivo, amparada por um sistema de regras. Tais jogos têm em sua estrutura a proposição de um desafio ou um objetivo a se

\footnotetext{
${ }^{2}$ Nomenclatura utilizada por Piaget para diferenciar os tipos de jogos: de exercício, simbólico e de regras, atentando para a dimensão competitiva voltada a um objetivo comum entre os jogadores.
} 
cumprir e, quando coletivos, envolvem o aspecto competitivo, pois implicam em apenas um vencedor. Essas propriedades do jogo de regras oportunizam o desenvolvimento de processos cognitivos, afetivos e sociais, que, quando analisados, podem fornecer informações relevantes quanto ao pensamento do sujeito.

O jogo pode se constituir em situação propícia para a observação de processos cognitivos, sociais e afetivos. A situação de jogo oferece ao sujeito impasses e situações-problema, demandando dele o desenvolvimento de estratégias para que seja capaz de jogar e, talvez, vencer (REBEIRO, 2012).

O jogo pode desencadear, através de sua estrutura, os mecanismos necessários ao processo de tomada de consciência como, por exemplo, ao ter o sujeito que controlar os meios e criar estratégias adequadas para vencer os obstáculos impostos pela situação lúdica.

Ao elaborar uma estratégia e empregá-la no jogo, o sujeito precisa levar em consideração não apenas suas ações, mas também a ação dos demais jogadores, que irá interferir em suas próximas jogadas. Ao iniciar um processo reflexivo sobre suas ações, realizando uma tomada de consciência sobre elas, o sujeito pode mudar sua estratégia, implicando em uma regulação de sua ação. Macedo (2009, p.50) alerta que “[...] em uma situação de jogo, o pensamento que reflete, faz inferências, classifica, ordena, toma decisões, teoriza ou contempla simultaneamente o próprio jogo e seu oponente deve se articular com um corpo que olha, escuta, age, sente e consente $[\ldots] "$.

Ao relacionar a teoria da equilibração à situação de jogo, Macedo (2009) destacou o papel dos observáveis e das coordenações. Na teoria da equilibração, os observáveis têm um papel de grande relevância, pois não tratam apenas do que o sujeito é capaz de perceber no momento, mas também o que compreende ou pensa a respeito. Observar compreende, também, a dimensão afetiva, pois envolve uma atribuição de sentido, e não pode ser dissociada da dimensão cognitiva.

Observáveis não se referem apenas ao que o sujeito percebe, pois seus esquemas de ação e estrutura cognitiva estão implicados na forma com que o sujeito percebe, auxiliando em uma visão mais precisa, ou acarretando em deformação. Os observáveis são, portanto, "o que a experiência permite constatar por uma leitura imediata dos fatos" (PIAGET, 1976, p. 46). 
As coordenações, por sua vez, consistem em inferências que o sujeito é capaz de realizar, constituem-se de relações estabelecidas pelo sujeito e que extrapolam os dados observados ou percebidos instantaneamente por ele. Podem apresentar-se equivocadas por serem muito limitadas ou generalizadas (PIAGET, 1976, p. 46).

O que um jogador é capaz de perceber de uma partida em um dado momento o leva a fazer inferências sobre quais são as próximas ações para obter sucesso, ou vitória. Os demais jogadores são afetados por essas ações, pois, individualmente, já poderiam estar estabelecendo suas estratégias individuais; a mudança de um componente do jogo (peça, carta etc.) produzida pela ação do adversário convida o jogador a estabelecer novas estratégias.

Ao pensar no papel da oficina de jogos na aprendizagem da segunda língua, relacionamos três pontos chaves da ação docente, destacados por Campos e Macedo (2011). Os autores discutem o papel mediador do professor, analisando os aspectos centrais: intencionalidade, reciprocidade e transcendência. Intencionalidade diz respeito à intervenção do professor, que mobiliza o aluno / sujeito, passando a compartilhar um foco comum, quando este percebe o sentido da tarefa e a assume como sua, solidariza em uma ação intencional, recíproca ao mediador. Transcender, neste caso, implica em ampliar o aprendido, estabelecendo relações com outras situações para além da experiência imediata.

A proposta de oficina de jogos deve contemplar a interdependência entre os fatores para que corresponda a uma vivência e oportunize aprendizagens de maior significado para os alunos.

\section{$3 \quad$ Metodologia}

A pesquisa qualitativa, de natureza descritivo-interpretativa, se circunscreveu no âmbito da observação, registro e análise dos dados, ou seja, na atribuição de significado àquilo que, enquanto pesquisador, se vivenciou ou observou (LÜDKE; ANDRÉ, 1986; GARCIA, 2010).

O objetivo geral do estudo foi analisar, no contexto de oficinas com jogos, aspectos cognitivos relacionados à aprendizagem da língua inglesa como idioma estrangeiro. Como 
objetivos específicos o estudo propôs reconhecer aspectos cognitivos relativos à aprendizagem da língua inglesa, manifestos pelos sujeitos nas oficinas de jogos.

Os participantes da pesquisa, 11 estudantes de uma escola estadual de Londrina-PR, foram selecionados por meio de sorteio entre todos os alunos de uma turma do 60 ano do ensino fundamental, realizado pela professora de inglês que utilizou os números da lista de chamada em uma das aulas semanais como critério para selecioná-los. O jogo utilizado na oficina foi produzido por uma das autoras. A oficina ocorreu duas vezes por semana, durante as aulas de inglês, em outro ambiente da escola, no período de três meses, totalizando 16 encontros. Ao selecionar os alunos para cada partida, a pesquisadora buscou fazer combinações entre os sujeitos de modo a oportunizar diferentes arranjos interpares. As sessões foram filmadas, com o apoio de uma pesquisadora auxiliar e ocorriam em espaço distinto da sala de aula, em mesas dispostas no pátio da escola.

A pesquisa atendeu às demandas éticas de pesquisa envolvendo seres humanos no Comitê de Ética em Pesquisa envolvendo seres humanos da Universidade Estadual de Londrina (CONEP 268) - parecer n. 288/2011.

\subsection{O Jogo: The English Game}

Intitulado The English Game, o jogo de tabuleiro consiste em um trajeto percorrido por peças, no qual cada espaço é demarcado por uma cor diferente (azul, verde, vermelho e amarelo), que corresponde a uma pilha de cartas separadas pelo mesmo código de cores. Cada cor implica em um tipo de carta contendo um desafio diferente, portanto, é atribuída uma escala de pontuação diferenciada para cada tipo de desafio. Os jogadores se organizam para começar a partida, jogando o dado; aquele que tirar o maior número inicia. Caso haja empate, apenas os jogadores que empataram jogam o dado novamente. O participante move sua peça e retira uma carta de cor correspondente ao espaço do tabuleiro no qual sua peça parou. Neste jogo, como conteúdos da língua inglesa, destacam-se o verbo ser/estar, os pronomes pessoais, saudações, além de um vocabulário variado (classes de palavras, como animais, cores, alimentos e objetos), como pode ser visto na Figura 1. 

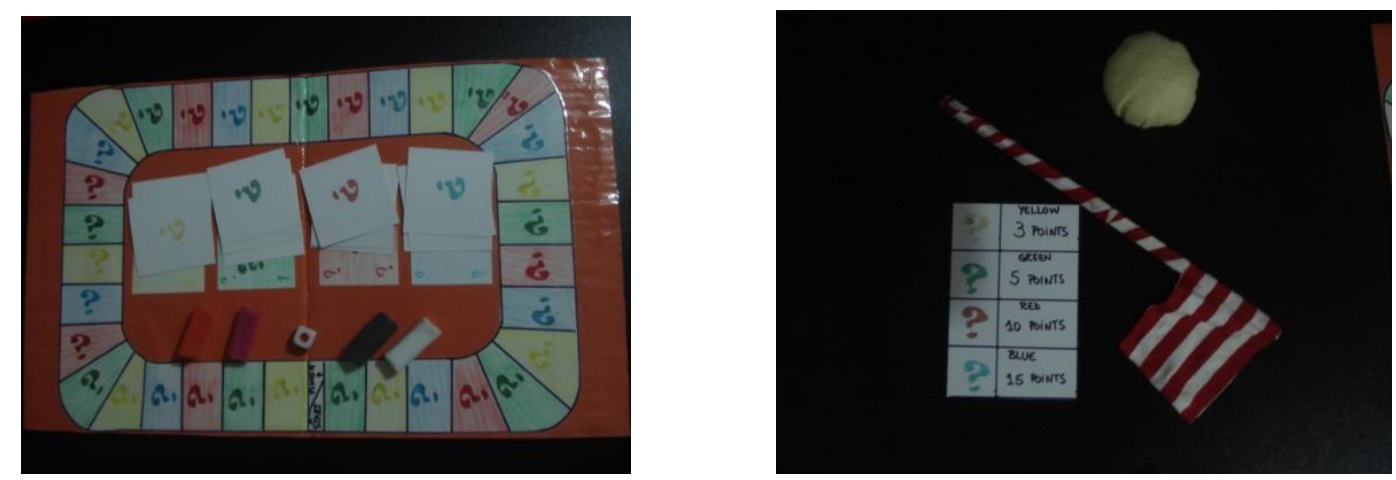

Figura 1 - Componentes do jogo The English game

Fonte: Elaboração Própria

Um objeto semelhante a uma bandeira pode ser confeccionado para que os participantes possam realizar correções ou resolver os desafios após os colegas e, assim, também ganhar os pontos referentes à carta utilizada no momento.

O jogo finaliza quando o tabuleiro é percorrido pelos jogadores. Somam-se os pontos. O jogador com o maior número de pontos vence a partida. Vale lembrar que cada jogador ou dupla deve dispor de papel e lápis para anotar os pontos, além de desenhar ou registrar as frases produzidas.

\section{Resultados: Aspectos cognitivos manifestados pelos sujeitos nas oficinas de jogos}

Os aspectos cognitivos envolvidos na aprendizagem abrem espaço para várias discussões. Entretanto, no sentido de estabelecer um recorte do que seria analisado, sem deixar de reconhecer a amplitude dos possíveis desdobramentos, os elementos selecionados para a análise dos aspectos cognitivos não foram determinados a priori, mas ao serem observados pela pesquisadora nas oficinas com os jogos, se tornaram objeto de análise.

Durante as primeiras explicações das regras dos jogos, realizadas integralmente em língua inglesa, os alunos pediam tradução de termos, faziam expressões faciais de estranhamento ou, ainda, pediam que as explicações fossem feitas em português pela pesquisadora. Mesclavam respostas na língua materna e na língua inglesa. A pesquisadora optou por apresentar a transcrição dos diálogos, mantendo destaque em itálico para as palavras ditas em inglês durante as oficinas. 
Nos momentos posteriores à explicação, a pesquisadora realizava a confirmação da compreensão, que consistia em verificar, em português, o que os participantes haviam compreendido. Alguns alunos afirmavam não ter compreendido a explicação, mas respondiam às questões, feitas em português, com informações da fala da pesquisadora expressa anteriormente, em inglês. Ao ouvir as mensagens que continham palavras conhecidas e desconhecidas, os jogadores se depararam com as lacunas de seu conhecimento e domínio da lingua não materna. Vejamos que, por exemplo, enquanto A10 aparenta estar mais inseguro a respeito das palavras que não sabe A4 permanece atento a outras pistas do ambiente, como os gestos e as expressões, o que o auxilia a compreender parte do que não conhece.

O fragmento de protocolo do jogador A4 demonstra que os gestos que acompanhavam as explicações da pesquisadora auxiliavam a compreensão, conforme apresentado a seguir:

P: Antes de vocês jogarem, quero saber - foi difícil entender minha explicação?

A10, A7, A4, A9: não.

$\mathrm{P}$ : que coisas vocês usaram para entender minha explicação? (silêncio)

A7: quando você fala inglês é difícil de entender.

P: vocês acham difícil, mas..
P: Then, A11 asks A8. Ok? Understand?

A10: não.

P: Fala, A10, qual é a tua dúvida?

A10: não entendi nada.

$\mathrm{P}$ : Você não entendeu

As lacunas, evidenciadas por interações que oferecem condições necessárias, mas não suficientes, geram perturbações. Estas podem ser incorporadas pelo sujeito, que buscará resolvê-las, ou negá-las, caso o sistema ainda não seja capaz de encontrar uma melhor forma de organização para responder à demanda da perturbação (GARCIA, 2010).

As lacunas também se tornaram evidentes na compreensão de $A 7$, em uma interação com $P$. No exemplo a seguir, A7 faz relações de significado para compreender o que P disse:
P: Do you want to play again? Let's play again?
A7: Fala de novo essa palavra.
P: Let's play again. (pausadamente). 
Por esse exemplo, podemos analisar que o sujeito A7 utilizou um esquema de ação que, muito provavelmente, é requerido na sala de aula. Compreende-se esquema, nesta perspectiva de análise, como "uma coordenação da ação, um 'saber fazer', por meio do qual o sujeito assimila os objetos às suas estruturas" (MACEDO, 1994, p. 148). Assim, é possível identificarmos, no procedimento desse jogador, que ele (A7) compreendeu a mensagem pelo seu conteúdo e contexto, mas precisou confirmar sua compreensão, traduzindo cada trecho da pequena frase. A7, nessa situação, associou palavras a significados, assimilou o conteúdo, mas não o integrou ou modificou esquemas, tendo em vista essa nova assimilação.

A4, por sua vez, percebeu lacunas na compreensão, mas as compensou, acompanhando os gestos de $\mathrm{P}$ e estabelecendo relações com palavras desconhecidas. A7 utilizou o esquema de tradução, com o qual está familiarizado, o que evidencia já possuir alguma compreensão das palavras desconhecidas com apoio em pistas do contexto. A4 também resolve o conflito, lançando mão da linguagem gestual. Em ambos os casos, a compreensão está apoiada em elementos que permeiam o significado da expressão, garantindo a comunicação. A10, por outro lado, não reconhece que compreende quando as informações são dadas em outra língua, afirmando que nada compreendeu, mas, quando responde às perguntas com as informações ditas em inglês, denota relativa compreensão da mensagem.

A dinâmica desse processo de aprimoramento, oportunizada pelo jogo, ocorre mediante assimilações constantes, tanto do objeto quanto das próprias escolhas ou meios empregados, permitindo que o sujeito busque o que é conhecido para si, em cada situação nova que lhe é apresentada e, a seguir, incorpore esse elemento novo à estrutura já existente.

O novo ou a novidade, nesse contexto de oficina de jogos, é a comunicação em outra língua. Esse novo demanda dos sujeitos não apenas a assimilação de termos em inglês, mas, também, uma nova forma de lidar com a língua, uma vez que o esquema de tradução termo a termo não se constitui por si só, suficiente, embora seja necessário para compreender as explicações das regras dos jogos e jogar bem o jogo. Os jogadores foram convidados a estabelecer um novo contato com a língua e, nesse novo contato, depararam-se com afirmações e negações, reveladoras das lacunas ou da insuficiência de seus esquemas diante da demanda do jogo. 
Na situação descrita a seguir, apresentamos os protocolos de jogo dos alunos $A 8, A 6$ e $A 2$, que precisavam falar nomes de alimentos em inglês. A8 fez algumas tentativas, mas reconheceu que as palavras pertencem a outro idioma, não tendo certeza se estão em inglês.

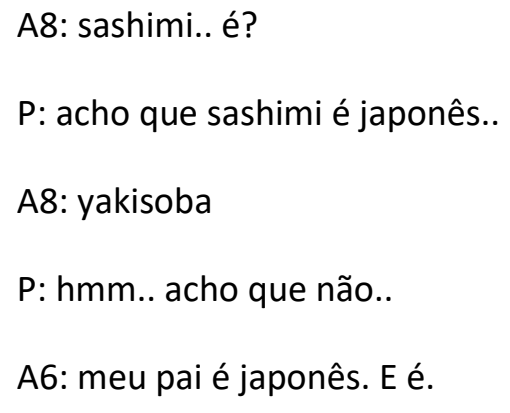

Em outro trecho da mesma partida, A2 não reconhece a contradição dos termos e recorre a uma palavra que pertence a outro idioma. Nesse sentido, é como se o conjunto de negação da palavra em português pudesse incorporar a palavra em qualquer outro idioma. Assim, diante da proposta de apresentar o termo em inglês, A2 oferece uma palavra qualquer que possa negar o termo em português. Após ser questionado pela pesquisadora, que intencionava manter o conflito cognitivo ativo, A2 tenta justificar sua resposta, reafirmando sua escolha. Observemos o fragmento do protocolo, a seguir:
A2: taiwan.
P: taiwan é alimento?
A6: não!
A2: taiwan fish.
P: é uma cidade não é?
A2: é aqui no centro.
P: é um restaurante?
A2: é um restaurante de peixe.
P: é o nome de um peixe, taiwan?

Nos trechos acima, vemos A6 e A8 percebendo a contradição. Ao se tornar observável, o erro permite que busquem alternativas para tentar equilibrar negações e afirmações, pois, 
se os termos apresentados não estão em inglês, o que seriam alimentos em inglês? $\mathrm{Na}$ condição de se tornar observável ao sujeito, a negação se constitui em perturbação. Observemos, por exemplo, a conduta de A8, que poderia ser nomeada do tipo beta. 0 jogador entrou em contato com o que o perturbava, reconhecendo como um desafio, e assim seus mecanismos de regulação foram acionados, incorporando esse elemento perturbador à realização de pequenas mudanças que se constituem enriquecimento do sistema (GARCIA, 2010).

A2, por sua vez, diante da contradição, utilizou uma palavra que não obedece aos critérios (ser em inglês e representar alimento), recorrendo ao nome de um restaurante como termo em inglês que está sendo requerido, apenas porque é uma palavra em outro idioma. Ou seja, trata-se de considerar o conjunto da negação, sem especificações: tudo o que não é em português servirá para responder à demanda proposta. Os questionamentos de $\mathrm{P}$ não foram suficientes para que A2 percebesse o erro, mantendo conduta tipo alfa, ou seja, por meio de sua ação de fabulação, nega a perturbação, que não é percebida como tal (PIAGET, 1976; GARCIA, 2010).

As perturbações são imprescindíveis no processo de equilibração. Elas estão implicadas no desequilíbrio cognitivo, uma vez que provocam relações entre afirmações e negações. Porém, o que garante o aprimoramento da estrutura cognitiva não é o desequilíbrio, mas, sim, a possibilidade de superá-lo. A reequilibração constitui-se na busca de um novo equilíbrio, aprimoramento, uma melhor forma de organização da estrutura cognitiva (DELVAL, 2002; MACEDO, 2009; GARCIA, 2010).

Em diversas ocasiões da oficina, a resolução de conflitos cognitivos ocorria ora individualmente, ora na interação entre jogadores. De acordo com Garcia (2010), além de reconhecer as perturbações, o sujeito precisa realizar regulações, derivando de feedbacks negativos ou positivos. Os feedbacks negativos referem-se aos erros e fracassos e levam a compensações ou correções. Já os feedbacks positivos envolvem ausência, seja de um objeto, de uma das condições necessárias para concluir a ação ou, ainda, de conhecimento necessário para resolver o conflito propiciado pela perturbação.

De acordo com Piaget (1976, p. 24), a regulação consiste em "retomada A' de uma ação A é modificada pelos resultados desta, logo quando de um efeito contrário dos resultados de $\mathrm{A}$ sobre seu novo desenvolvimento $A^{\prime \prime \prime}$. 
Discutimos, agora, as regulações que ocorrem por meio dos feedbacks positivos. No trecho da jogada a seguir, exemplificamos uma regulação da ação a partir de feedbacks positivos cuja proposição requeria que os jogadores produzissem uma frase contemplando dois critérios: usar o verbo to be e o pronome pessoal we.

Os sujeitos A6 e A2 conseguem se lembrar das três formas do verbo to be e do significado do pronome pessoal we. Ou seja, nessa ocasião, dispõem dos elementos necessários para realizar a tarefa. Nas primeiras tentativas, A6 e A2 percebem que elas são insuficientes. Os sujeitos conseguem produzir uma frase que comporte os critérios pedidos.

Do ponto de vista gramatical, a sentença não está correta, porém é possível perceber uma regulação, uma vez que os sujeitos refazem suas produções a fim de alcançar um resultado mais apropriado à demanda. No trecho a seguir, o mesmo sujeito A2 regula sua ação e produz uma sentença, estabelece hipóteses e, posteriormente, desenvolve uma maneira diferente de organizar as palavras, adequando-as à demanda da tarefa e ao sentido da frase. Observemos os trechos de protocolos a seguir:

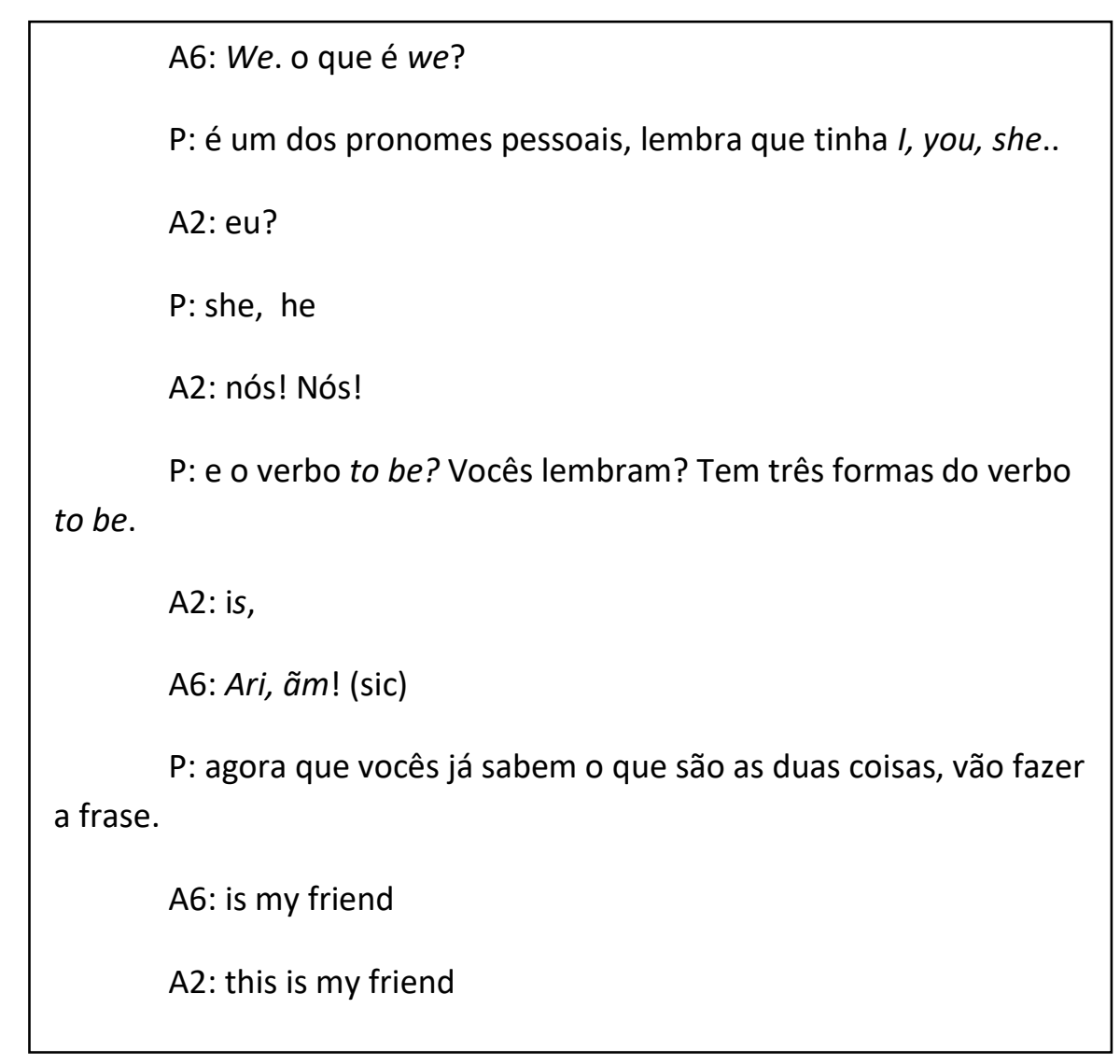




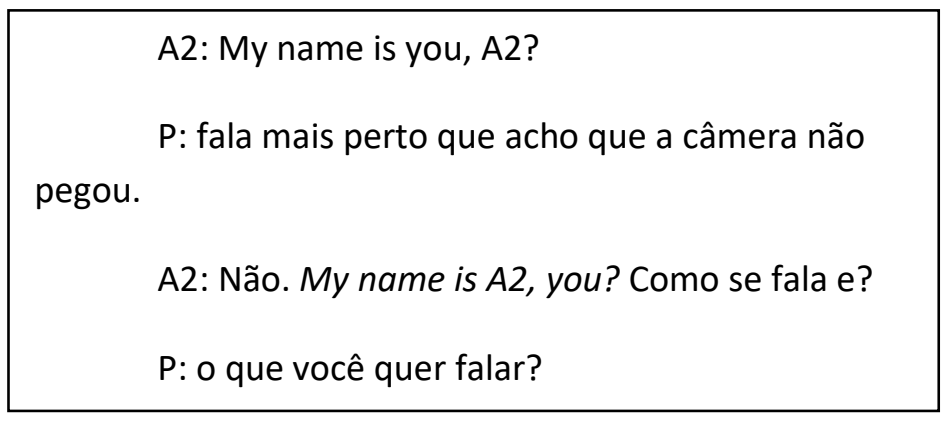

A primeira tentativa de A2 mostrou-se ineficaz, porém, ao estabelecer novas hipóteses, o sujeito chegou a uma forma que satisfez os critérios de produção. A observação desse fragmento de jogo nos aponta como reflexão o fato de que a dinâmica do jogo convida os sujeitos a repensarem suas estratégias e provoca seu pensamento para que uma melhor forma de organização seja alcançada. No entanto, para que ocorra esse aprimoramento do sistema cognitivo, são necessários o envolvimento do jogador, a compreensão das regras e o reconhecimento das perturbações provocadas pelas situações.

A dimensão do compreender, ou da tomada de consciência da ação, tem como foco não mais o resultado, mas, sim, seu sentido, pois sua busca consiste no entendimento dos meios e das razões que produzem um determinado desfecho. "O plano da compreensão é o do domínio da estrutura, do sistema que regula a ocorrência de um certo fenômeno" (MACEDO, 1994, p. 76).

Ao longo das jogadas do The English Game percebemos que as produções dos alunos poderiam ser utilizadas de modo a possibilitar momentos de autocorreção e reflexão sobre a elaboração de frases na língua inglesa. Optamos por recuperar, pelas filmagens e registros por escrito, as produções dos alunos realizadas nas sessões do jogo e desenvolvemos uma nova proposta. Realizamos, então, uma última jogada com 10 jogadores (um dos sujeitos não estava presente na escola naquela data), divididos em duplas e trios, substituindo as cartas originalmente propostas por novas cartas que continham as produções realizadas nas jogadas anteriores. $\mathrm{O}$ objetivo era que os alunos pudessem rever frases corretas e incorretas do ponto de vista gramatical, produzidas por eles nas oficinas anteriores, oportunizando uma correção ou uma revisão das produções realizadas. Foram mantidas as regras do jogo e a escala de pontuação. As sentenças foram subdivididas entre as quatro cores do tabuleiro, de acordo com a escala de pontuação que diferenciava o valor das cartas.

$\mathrm{Na}$ última sessão da oficina, foram constituídos três grupos e as cartas do jogo foram substituídas por frases produzidas pelos jogadores durante as partidas anteriores. Optamos 
por apresentá-la destacadamente, para analisarmos as oficinas com jogos como espaço para aprendizagem do inglês.

No excerto a seguir, os jogadores A3 e A5 dialogam sobre a sentença: My name is Bob and Lisa. Ambos perceberam erros nas frases e justificaram a correção (mesmo que parcial), pautados no sentido geral da frase e no significado de my (meu).

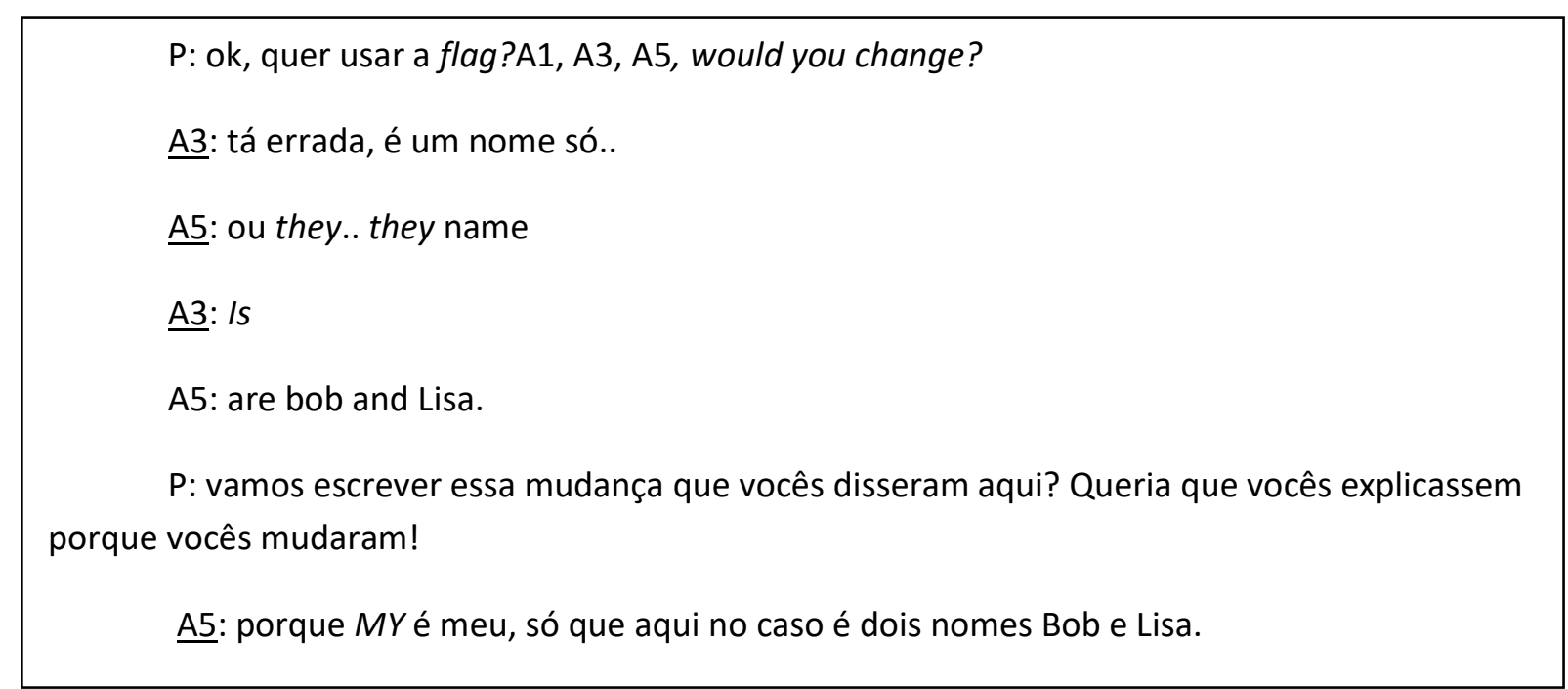

Observemos a situação descrita a seguir. Em uma determinada jogada, o grupo branco recebeu a carta com a frase You is birifou, intencionando dizer "você é bonita". A3 e A5 falam sobre o uso do verbo to be e realizam modificações para que haja concordância do ponto de vista gramatical. O protocolo apresentado a seguir é referente ao diálogo de A3 e A5, na solução desse impasse.

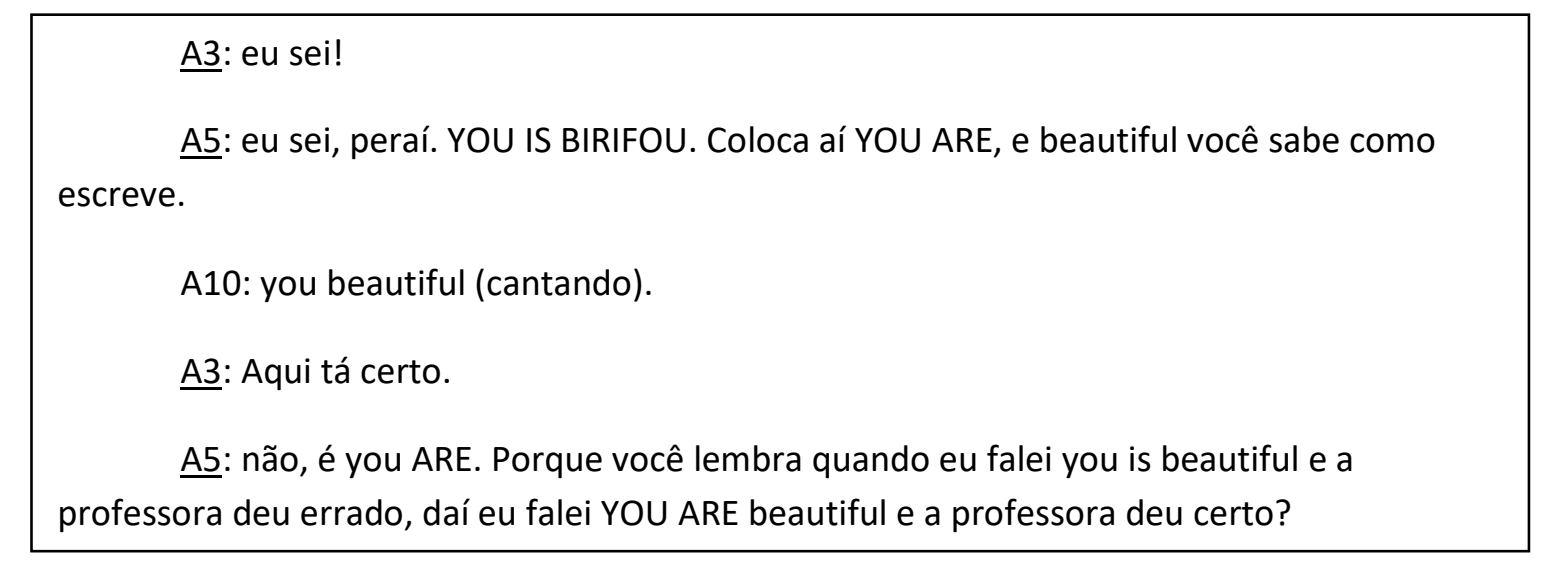

O sujeito A5 corrige a primeira parte da frase, baseando-se em experiências anteriores pautadas em tentativa, erro e acerto. A modificação executada por A5 é correta, do ponto de vista gramatical, e o resultado a que chegam é satisfatório para ambos e provavelmente 
seria satisfatório em um contexto de teste. Contudo, não podemos afirmar, por meio desse exemplo, que A5 compreendeu as regras gramaticais implicadas em sua decisão.

Avaliar o aluno, pautando-se apenas no produto, não garante que o processo esteja correspondendo ao progresso (ou acerto) evidenciado por suas respostas. O contexto de jogo oferece a oportunidade para o professor entrar em contato com as justificativas dos alunos para determinadas escolhas. Isso propicia uma avaliação mais aprofundada acerca dos procedimentos do aluno, não restrita ao resultado apresentado. Acessar o pensamento do aluno sobre suas produções por essa via pode constituir-se como parte da avaliação do processo de aprendizagem do sujeito.

\section{Considerações finais}

Sem ação do sujeito não há comunicação. O meio (colegas, professores, no caso da escola) representa possibilidades de promover desequilíbrios cognitivos que poderão desencadear processos de construção do conhecimento. Assim, quando um sujeito se envolve em uma comunicação na língua estrangeira, buscando transmitir uma mensagem com suas palavras, pode ser compreendido, ou pode ser questionado. As intervenções provocadas por fatores como leitura de novos textos, apresentação de novas possibilidades de formação de frases, comunicação oral ou escrita em parceria com outros sujeitos emitem importantes feedbacks. Ao compreenderem a mensagem, por exemplo, os sujeitos que se tornam coautores na interlocução com o autor confirmam que ele foi capaz de produzir mensagem. Ou ainda, ao não compreenderem a mensagem e devolverem um questionamento, apontam lacunas ao outro, o que pode desencadear uma busca por formas mais elaboradas de comunicação.

Ao refletir sobre a oficina de jogos como um cenário propício para a aprendizagem da língua estrangeira, destacamos que: suscitam a ação do sujeito que deve produzir algo de acordo com a consigna, utilizando seus esquemas para construir e comunicar na LE; evidenciam lacunas no conhecimento ou confirmam produções bem elaboradas à partir das interações comunicativas entre os jogadores, ou correspondência às demandas do jogo para comunicação na língua estrangeira; possibilitam a reflexão sobre produções próprias a fim de aprimorá-las do ponto de vista gramatical e levam o sujeito a utilizar o que conhece da LE 
para produzir, suscita a ação prática, saber fazer ou saber como se comunicar na LE. Na medida em que o sujeito se envolve na tarefa, é convidado a estabelecer correlações entre conteúdo e forma, estabelecendo relações de significado, aprendendo uma nova língua. $\mathrm{Na}$ oficina proposta, os sujeitos se depararam com a alternância entre situações comunicativas e demandas referentes aos conhecimentos da língua inglesa. Alternar situações de jogo com atividades de instrução formal pode ser uma estratégia promissora. Observar o jogo e como seus participantes elaboram suas estratégias fornece dados importantes sobre a organização cognitiva do sujeito. A situação de jogo pode ser propícia para que o sujeito enfrente contradições e lacunas do seu processo de construção do conhecimento.

Manter o conflito cognitivo ativo pode auxiliar os alunos na busca pela eliminação de contradições, superação do conflito cognitivo e novo equilíbrio. A prática de jogos nas aulas de inglês provoca, como reflexão, a necessidade de repensarmos a visão dissociada entre jogar e aprender, pois é possível aprender jogando e jogar aprendendo. Consideramos importante uma investigação que venha ampliar a análise que realizamos acerca dos aspectos cognitivos no processo de aprendizagem da segunda língua, com o uso de jogos, no ambiente da sala de aula.

\section{Referências}

BRASIL. [Lei Darcy Ribeiro (1996)]. LDB: Lei de Diretrizes e Bases da Educação Nacional: lei no 9.394, de 20 de dezembro de 1996, que estabelece as diretrizes e bases da educação nacional. - 5. ed. - Brasília: Câmara dos Deputados, Coordenação Edições Câmara, 2010. Disponivel em: http://bd.camara.gov.br >. Acesso em: 20 set. 2011.

BRASIL. Secretaria de Educação Fundamental. Parâmetros curriculares nacionais: terceiro e quarto ciclos do ensino fundamental: língua estrangeira / Secretaria de Educação Fundamental. Brasília: MEC/SEF, 1998. Disponível em: http://portal.mec.gov.br > . Acesso em: 20 set. 2011.

CAMPOS, M.C.R.M.; MACEDO, L. de Desenvolvimento da função do professor em oficinas de jogos. Revista Semestral da Associação Brasileira de Psicologia Escolar e Educacional, São Paulo, v. 15, n. 2, p.211-220, Jul-Dez. 2011.

DELL'AGLI, B. A. V. Os jogos de regras como um recurso diagnóstico psicopedagógico. 2002. 199 f. Dissertação (Mestrado em Educação) - Universidade Estadual de Campinas, Campinas, 2002. 
DELVAL, J. Introdução à prática do método clínico: descobrindo o pensamento das crianças. Trad. Fátima Murad. Porto Alegre: Artmed, 2002.

DUARTE, M. S. A reforma do ensino de língua inglesa no Brasil. Inter-Ação: Rev. Fac. Educ. UFG, Goiás, v. 32, n. 1, p. 173-199, jan./jun. 2007.

GARCIA, H. H. G. O. Adolescentes em grupo: aprendendo a cooperar em oficina de jogos. 2010. 275 f. Tese (Doutorado em Psicologia) - Universidade de São Paulo, São Paulo, 2010. Disponível em: http://dgp.cnpq.br>. Acesso em: 12 jul. 2011.

GUERRA, M. M.; CAMARGO, M.R.R.M. Educandas do PEJA em: conversas sobre a língua inglesa e sua influência no cotidiano. Educação: teoria e prática, Rio Claro, v. 22, n. 39, p.139-159, jan-abr. 2012.

LÜDKE, M.; ANDRÉ, M.E.D.A. Pesquisa em educação: Abordagens qualitativas. São Paulo: EPU, 1986.

MACEDO, L. Teoria da Equilibração e jogo. In: (Org.) Jogos, psicologia e educação. São Paulo: Casa do Psicólogo, 2009. p.21-43.

MACEDO, L. Ensaios Construtivistas. São Paulo: Casa do Psicólogo, 1994.

MONTANGERO, J.; MAURICE-NAVILLE, D. Piaget ou a Inteligência em evolução. Trad. Tânia Beatriz Iwaszko Marques. Porto Alegre: Artmed, 1998.

PIAGET, J. A linguagem e o Pensamento da criança. Trad. Manuel Campos, Marina Appenzeller e Áurea Regina Sartori. Inserir edição, a partir da 2a. . São Paulo: Martins Fontes, 1993.

PIAGET, J. A equilibração das estruturas cognitivas: problema central do desenvolvimento. Trad. de Alvaro Cabral, Rio Janeiro: Zahar: 1976.

PIAGET, J. A formação do símbolo na criança. Trad. De Alvaro Cabral, 2ª ed. Rio de Janeiro: Zahar, 1975.

PIRES S.S. Ensino de inglês na educação infantil. In: SARMENTO, S. ; MÜLLER, V. (Orgs). 0 ensino do inglês como língua estrangeira: estudos e reflexões. Porto Alegre: APIRS, 2004. p.204-232.

REBEIRO, G.B. F. Fatores protetivos e o jogo de regras Rummikub: um estudo com alunos do 60 ano do Ensino Fundamental. 2012. 119 f. Dissertação (Mestrado em Educação) Universidade Estadual de Londrina, Londrina, 2012. 